\title{
A STUDY OF DETECTION OF MYCOBACTERIA BY FLUORESCENCE MICROSCOPY IN IMPRINT SMEAR AND ZIEHL-NEELSEN STAIN IN TISSUE SECTION FROM SKIN BIOPSY SPECIMEN
}

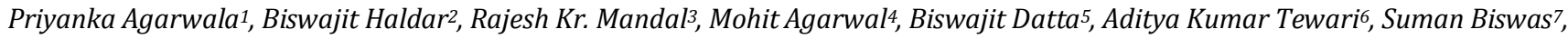 \\ Subrata Bhattacharjee 8
}

\begin{abstract}
${ }^{1}$ Consultant Pathologist, Department of Pathology, 3gen Diagnostics (A Unit of North Bengal Healthcare Pvt. Ltd.), Siliguri, Darjeeling, West Bengal, India.

2Associate Professor, Department of Pathology, North Bengal Medical College, Sushrutanagar, Darjeeling, West Bengal, India. ${ }^{3}$ Assistant Professor, Department of Dermatology, North Bengal Medical College, Sushrutanagar, Darjeeling, West Bengal, India. ${ }^{4}$ Resident, Department of Pulmonology, ESIC Model Hospital, Basai Darapur, New Delhi, India.

5 Professor and HOD, Department of Urology, North Bengal Medical College, Sushrutanagar, Darjeeling, West Bengal, India. ${ }^{6}$ Radiologist, Department of Radiology, 3gen Diagnostics (A Unit of North Bengal Healthcare Pvt. Ltd.), Siliguri, Darjeeling, West Bengal, India.

${ }^{7}$ Postgraduate Trainee, Department of Anaesthesiology, North Bengal Medical College, Sushrutanagar, Darjeeling, West Bengal, India. ${ }^{8}$ Demonstrator, Department of Pathology, North Bengal Medical College, Sushrutanagar, Darjeeling, West Bengal, India.
\end{abstract}

\section{BACKGROUND}

ABSTRACT

Over the years, a number of methods have been tried to detect the presence of Mycobacteria in tissue samples. A number of previous literatures are available comparing the efficacy of fluorescent microscopy with Ziehl-Neelsen (ZN) stain for the detection of acid-fast bacilli (AFB) in tissue sections, but very few literatures are available on the efficacy of fluorescent method in imprint smears taken from skin biopsy over ZN method in tissue sections. Thus, the present study was undertaken with the following objective- to study the efficacy and advantages of using fluorescent microscopy in imprint smear from skin biopsies over ZN method in tissue sections for detection of mycobacteria in clinically suspected cases of leprosy and cutaneous tuberculosis.

\section{MATERIALS AND METHODS}

80 patients with a clinical suspicion of leprosy and cutaneous tuberculosis were biopsied \& imprint smears taken. Imprint smears were air-dried and stained with Auramine 0, and the skin biopsy samples were processed for routine histopathology and ZN Staining. Results were then analysed.

\section{RESULTS}

Out of 80 imprint smears, 65 were studied (remaining 15 were excluded from the study as per exclusion criteria), of which $40 \%$ (26/65) were positive for AFB on ZN method, while the smear positivity increased to $49.2 \%$ (32/65) on the fluorescent method.

\section{CONCLUSION}

Fluorescent microscopy has the advantage of speed and ease of screening and reduces observer fatigue and found to be more advantageous than conventional ZN method, particularly in paucibacillary and low mycobacterial load cases. Hence, fluorescent method can be an adjuvant when used with routine histopathology for the identification of AFB.

\section{KEY WORDS}

Imprint Smear, Fluorescent Method, Ziehl-Neelsen Stain.

HOW TO CITE THIS ARTICLE: Agarwala P, Haldar B, Mandal RK, et al. A study of detection of mycobacteria by fluorescence microscopy in imprint smear and ziehl-neelsen stain in tissue section from skin biopsy specimen. J. Evolution Med. Dent. Sci. 2019;8(06):359-363, DOI: 10.14260/jemds/2019/79

\section{BACKGROUND}

Over the years, a number of methods have been tried to detect the presence of Mycobacteria in tissue samples. Culture is the reference method for detection of mycobacteria, but it is time consuming and requires specialized procedures in laboratories. Serological techniques have the disadvantage of lack of sensitivity and specificity. ${ }^{1} \mathrm{ZN}$ Stain plays a major role in diagnosing and monitoring patients who are on treatment for leprosy and cutaneous tuberculosis.

'Financial or Other Competing Interest': None.

Submission 07-01-2019, Peer Review 01-02-2019,

Acceptance 04-02-2019, Published 11-02-2019.

Corresponding Author:

Dr. Biswajit Haldar,

A-10/15, Uttorayon, Matigara,

Siliguri-734010, Darjeeling, West Bengal, India.

E-mail: biswajitpath@gmail.com

DOI: $10.14260 /$ jemds $/ 2019 / 79$ to $43 \%{ }^{1,2}$ Numerous studies have indicated, the superiority of fluorescence microscopy over $\mathrm{ZN}$ stain in detection of mycobacteria in tissue sections.3,4,5 In these studies, it was evident that fluorochrome staining offered greater ease and speed in detection of Mycobacteria. Newer molecular techniques such as polymerase chain reaction (PCR), although rapid, are costly to be routinely used in developing countries where most leprosy and cutaneous TB cases occur. Hence, a method for the identification of acid-fast bacilli (AFB) which is more sensitive and time saving than the $\mathrm{ZN}$ method is required for early detection of Mycobacterium.

The aim of this study is to correlate the fluorescent method in imprint smear with the ZN method in tissue section for the detection of AFB and, also to study the efficacy and advantages of using the Auramine 0 stain on imprint smear under fluorescent microscopy as a fast, efficacious and alternative method of detecting Mycobacterial infection. 
TT accounted for the most number of cases in 17 (26\%) cases, followed by LL in 15 (23\%) cases \& LV in 13 (20\%) cases. There was only a single case of TVC. There were no cases of borderline borderline leprosy (BB).

Fluorescent method of staining showed a better positivity in $3(17.6 \%)$ cases and $5(45.4 \%)$ cases in paucibacillary conditions than ZN method which showed positivity in $2(11.7 \%)$ cases and $3(27.2 \%)$ cases respectively. The methods showed equivalent positivity for LL. In this study, there was no detection of Mycobacteria in LV cases by any of the methods. Fluorescent method showed an overall positivity of $49.2 \%$ as compared to $40 \%$ for ZN Stain method.
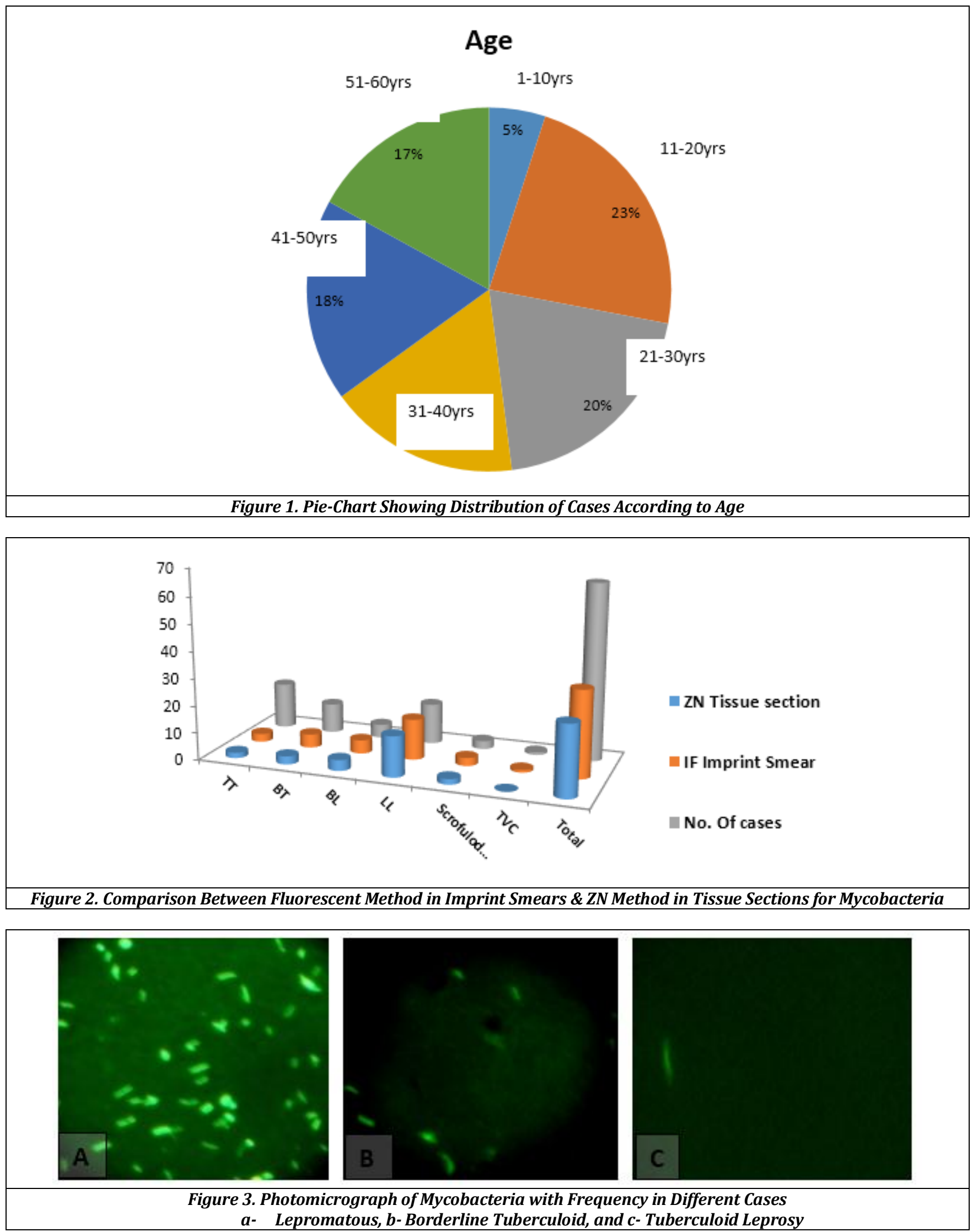


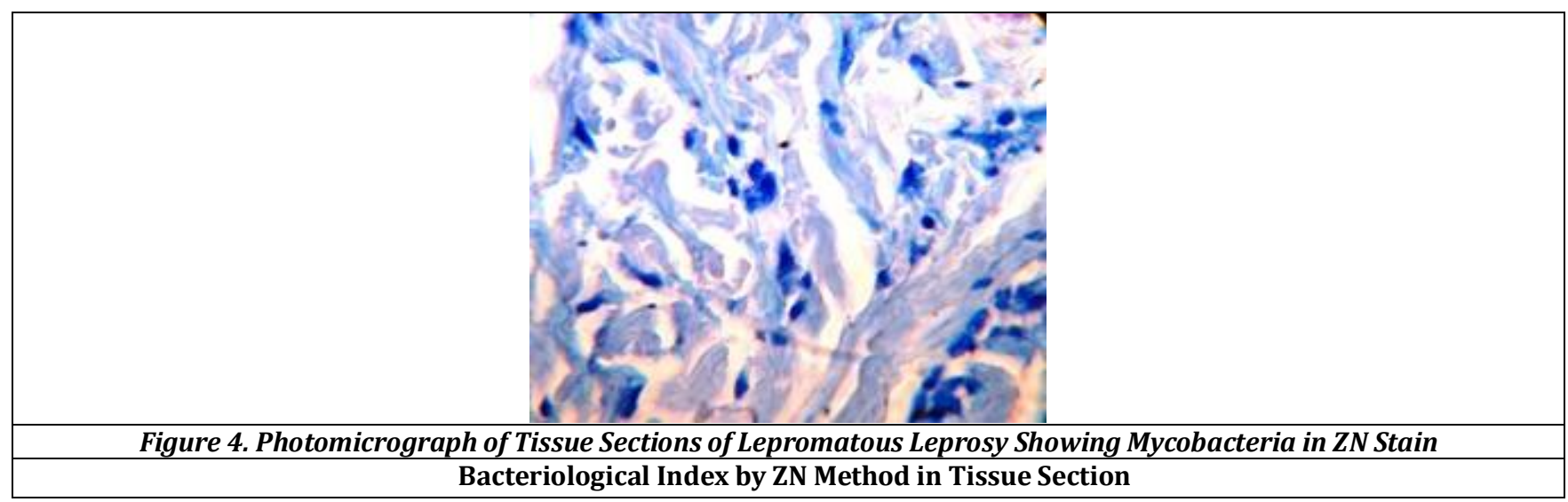

\begin{tabular}{|c|c|c|c|c|c|c|c|c|}
\hline \multirow{2}{*}{ Diagnosis } & $\mathbf{0 +}$ & $\mathbf{1 +}$ & $\mathbf{2 +}$ & $\mathbf{3 +}$ & $\mathbf{4 +}$ & $\mathbf{5 +}$ & $\mathbf{6 +}$ & $\begin{array}{c}\text { Total } \\
\text { Nos. }\end{array}$ \\
\cline { 2 - 9 } & $\mathbf{0 +}$ & $02(11.7 \%)$ & $0(0 \%)$ & $0(0 \%)$ & $0(0 \%)$ & $0(0 \%)$ & $0(0 \%)$ & 17 \\
\hline TT & $15(88.3 \%)$ & $03(27.2 \%)$ & $0(0 \%)$ & $0(0 \%)$ & $0(0 \%)$ & $0(0 \%)$ & $0(0 \%)$ & 11 \\
\hline BT & $08(72.8 \%)$ & $0(0 \%)$ & $0(0 \%)$ & $03(60 \%)$ & $02(40 \%)$ & $0(0 \%)$ & $0(0 \%)$ & 05 \\
\hline BL & $0(0 \%)$ & $0(0 \%)$ & $0(0 \%)$ & $0(0 \%)$ & $05(33.3 \%)$ & $06(40 \%)$ & $04(26.6 \%)$ & 15 \\
\hline LL & $0(0 \%)$ & $0(0 \%)$ & $0(0 \%)$ & $0(0 \%)$ & $0(0 \%)$ & $0(0 \%)$ & $0(0 \%)$ & 13 \\
\hline LV & $13(100 \%)$ & $02 \%)$ & $0(0 \%)$ & $0(0 \%)$ & $0(0 \%)$ & $0(0 \%)$ & 03 \\
\hline Scrofuloderma & $01(33.3 \%)$ & $02(66.7 \%)$ & $0(0 \%)$ & $0(0 \%)$ & $0(0 \%)$ & $0(0 \%)$ & $0(0 \%)$ & 01 \\
\hline TVC & $01(100 \%)$ & $0(0 \%)$ & $0(0 \%)$ & $0(0 \%)$ & $0(0 \%)$ & \\
\hline \multicolumn{7}{|c|}{ Table 4. Bacteriological Index By ZN Method in Tissue Section } \\
\hline
\end{tabular}

\begin{tabular}{|c|c|c|c|c|c|c|c|c|}
\hline \multicolumn{9}{|c|}{ Bacteriological Index by Fluorescent Method } \\
\hline \multirow{2}{*}{ Diagnosis } & \multicolumn{7}{|c|}{ Number and Percentage of Cases } & \multirow{2}{*}{$\begin{array}{l}\text { Total } \\
\text { Nos. }\end{array}$} \\
\hline & $\mathbf{0 +}$ & $1+$ & $2+$ & $3+$ & $4+$ & $5+$ & $6+$ & \\
\hline TT & $14(82.4 \%)$ & $03(17.6 \%)$ & $0(0 \%)$ & $0(0 \%)$ & $0(0 \%)$ & $0(0 \%)$ & $0(0 \%)$ & 17 \\
\hline BT & $06(54.5 \%)$ & $04(36.3 \%)$ & $01(9.2 \%)$ & $0(0 \%)$ & $0(0 \%)$ & $0(0 \%)$ & $0(0 \%)$ & 11 \\
\hline $\mathrm{BL}$ & $0(0 \%)$ & $0(0 \%)$ & $0(0 \%)$ & $01(20 \%)$ & $04(80 \%)$ & $0(0 \%)$ & $0(0 \%)$ & 05 \\
\hline LL & $0(0 \%)$ & $0(0 \%)$ & $0(0 \%)$ & $0(0 \%)$ & $0(0 \%)$ & $05(33.3 \%)$ & $10(66.6 \%)$ & 15 \\
\hline $\mathrm{LV}$ & $13(100 \%)$ & $0(0 \%)$ & $0(0 \%)$ & $0(0 \%)$ & $0(0 \%)$ & $0(0 \%)$ & $0(0 \%)$ & 13 \\
\hline Scrofuloderma & $0(0 \%)$ & $02(66.7 \%)$ & $01(33.3 \%)$ & $0(0 \%)$ & $0(0 \%)$ & $0(0 \%)$ & $0(0 \%)$ & 03 \\
\hline TVC & $0(0 \%)$ & $01(100 \%)$ & $0(0 \%)$ & $0(0 \%)$ & $0(0 \%)$ & $0(0 \%)$ & $0(0 \%)$ & 01 \\
\hline
\end{tabular}

\begin{tabular}{|c|c|c|}
\hline $\begin{array}{c}\text { Bacterial } \\
\text { Index }\end{array}$ & $\begin{array}{c}\text { Ziehl-Neelsen } \\
\text { Method }\end{array}$ & $\begin{array}{c}\text { Fluorescent } \\
\text { Method }\end{array}$ \\
\hline 0 & 38 & 33 \\
\hline $1+$ & 07 & 10 \\
\hline $2+$ & 0 & 02 \\
\hline $3+$ & 03 & 01 \\
\hline $4+$ & 07 & 04 \\
\hline $5+$ & 06 & 05 \\
\hline $6+$ & 04 & 10 \\
\hline \multicolumn{3}{|c|}{ Table 6. Comparison of Bacterial Index Between ZN } \\
Method in Tissue Sections \& The Fluorescent Method in \\
Imprint Smears \\
\hline
\end{tabular}

\begin{tabular}{|c|c|c|c|c|c|c|}
\hline & \multicolumn{2}{|c|}{$\begin{array}{c}\text { Nayak SV } \\
\text { et al }\end{array}$} & \multicolumn{2}{|c|}{$\begin{array}{c}\text { Jariwala HJ } \\
\text { et al, }\end{array}$} & \multicolumn{2}{c|}{$\begin{array}{c}\text { Our } \\
\text { Study }\end{array}$} \\
\hline & No. & $\mathbf{( \% )}$ & No. & $\mathbf{( \% )}$ & No. & $\mathbf{( \% )}$ \\
\hline $\begin{array}{c}\text { Total Number of } \\
\text { Cases Studied }\end{array}$ & 56 & $100 \%$ & 50 & $100 \%$ & 65 & $100 \%$ \\
\hline $\begin{array}{c}\text { Positivity in } \\
\text { Fluorescence } \\
\text { Method }\end{array}$ & 39 & $69.64 \%$ & 22 & $44 \%$ & 32 & $49.23 \%$ \\
\hline $\begin{array}{c}\text { AFB Detected in } \\
\text { Tissue Section }\end{array}$ & 25 & $44.64 \%$ & 20 & $40 \%$ & 26 & $40 \%$ \\
\hline
\end{tabular}

Table 7. Comparison Between Different Study and Our Study of Sensitivity of Zn Method in Tissue Sections \& The Fluorescent Method
There were 5 such cases which did not show bacilli in ZN method had a bacterial index of $1+$ or 2+ in Fluorescent method. Fluorescent staining depicted a higher bacteriological index in most cases, signifying a better detection of bacillary load.

\section{DISCUSSION}

Prompt detection of Mycobacterial infection is a necessity for diagnosis as well as treatment. Early detection is important to avoid deformities. The diagnosis is confirmed by demonstration of Mycobacterium in tissue samples taken from the lesion.

Hagemann, in 1937, was the first to demonstrate the fluorescence of both Mycobacterium tuberculosis and Mycobacterium leprae when these bacteria were stained with berberine sulphate. 6 In 1938, he demonstrated better fluorescent-staining of these mycobacteria with phenolauramine. ${ }^{7}$

We found that the positivity of fluorescent stain from imprint smears were $100 \%$ when compared to modified ZN Stain in tissue sections while detecting multibacillary $\mathrm{M}$. leprae, scrofuloderma and tuberculosis verucosa cutis. These results were similar to the finding of Nayak, ${ }^{8}$ Jariwala, ${ }^{5}$ Bhatia ${ }^{9}$ and Mansfield et al. ${ }^{4}$ who carried out fluorescent staining in 
tissue sections. However, Lacordaire 10 observed that fluorescent staining method was inferior.

The positivity for fluorescence staining from smears were $45.4 \%$ and $17.6 \%$ while detecting BT and TT cases compared to $11.7 \%$ and $27.2 \%$ respectively for $\mathrm{ZN}$ stained tissue sections.

The AFB typically fluoresce as golden, slender, rod-shaped bacilli, but they may appear curved or bent. Also, some individual AFB may display heavily stained areas referred to as beads and/or alternating light and dark areas of stain producing a banded appearance. Although the ability to retain aryl methane dyes, such as Auramine 0, after washing with alcohol or weak acids is a primary feature of the genus Mycobacterium, it is not entirely unique to the genus. Other bacteria, which contain mycolic acids, such as Nocardia, can also exhibit this feature. The exact method by which the stain is retained is unclear, but it is thought that the stains become trapped within the cell or may form a complex with the mycolic acids.

A good observation is required to distinguish with certainty AFB from other small, naturally fluorescent particles present in some smears. When first using fluorescent microscopy, it is necessary to examine all small fluorescent objects seen both with the $\times 10$ and $\times 40$ objectives. With practice, it becomes possible to distinguish bacilli with a fair degree of certainty under the $\times 10$ objective only, so that almost all negative smears can be examined with this objective only.

\section{Pitfalls}

The study process was not without its share of problems and hitches. The main problem which we faced was that of thin quality imprint smears, artifactual fluorescence \& photobleaching of fluorescent stain. If the smear is too this, there is a possibility of the smear getting washed off during the staining procedure and yielding negative results.

Secondly, artefacts from the fluorochrome staining, together with interference from primary or secondary fluorescence of tissue compounds, increased the likelihood of false-positive results.

Moreover, morphological differentiation between Mycobacteria was not possible by fluorescent staining. Subsequent $\mathrm{H} / \mathrm{P}$ examination remains a necessity.

These problems and obstacles can however be overcome by regular practice and carefully following procedures.

\section{CONCLUSION}

The use of the fluorescent method greatly improves the diagnostic value especially in patients with a low density of bacilli that are likely to be missed on $\mathrm{ZN}$-stained smears. The speed of observation and the rapidity of finding the bacilli by fluorescent microscopy reduced observer's fatigue because the bright bacilli stand out in dark background. The fluorescent-stained smears can be examined under low magnification allowing for much larger areas of the smear to be examined in a much short span of time. Prompt detection of Mycobacterium would provide an important clue to the clinician and act as an aid to diagnosis \& early treatment. Detection of bacilli by fluorescent method greatly improves its diagnostic value in AFB negative $\mathrm{ZN}$-stained sections. It can be considered as an effective screening tool. Large scale study is needed to corroborate the findings.

Hence, it would be beneficial to use fluorescence method as an adjunctive, fast, efficacious method of detecting mycobacterial infections.

\section{REFERENCES}

[1] Daniel TM. Rapid diagnosis of tuberculosis: laboratory techniques applicable in developing countries. Rev Infect Dis 1989;(11 Suppl 2):471-8.

[2] Balows A, Hausler WJ, Herrmann KL, et al. Manual of clinical microbiology. $5^{\text {th }}$ edn. Washington, D.C.: American Society for Microbiology 1991: p. 308-11.

[3] Gohar MA. A note on fluorescence microscopy in the diagnosis of leprosy. J Trop Med Hyg 1952;55(7):1567.

[4] Mansfield RE. An improved method for the fluorochrome staining of mycobacteria in tissues and smears. Am J Clin Pathol 1970;53(3):394-406.

[5] Jariwala HJ, Kelkar SS. Fluorescence microscopy for detection of Mycobacterium Leprae in tissue sections. Internal Journal of Leprosy Other Mycobact Dis 1979;47(1):33-6.

[6] Hagemann PKH. Fluorescence of Mycobacterium tuberculosis and Mycobacterium Leprae with berberine sulfate solution. Deutsche Med Wschr 1937;63:514.

[7] Hagemann PKH. Fluorescence of mycobacteria with auramine. Munchen Med Wschr 1938;85:1066.

[8] Nayak SV, Shivarudrappa AS, Mukkamil AS. Role of fluorescent microscopy in detecting Mycobacterium leprae in tissue sections. Annals of Diagnostic Pathology 2003;7(2):78-81.

[9] Bhatia VN, Rao S, Saraswathi G. Auramine staining in histopathology sections. Indian J Lepr 1987;59(4):3869.

[10] De Faria LL. Fluorescent staining of Mycobacterium Leprae in tissue sections comparison with Fite - Faraco procedure. Internal Journal of Leprosy 1974;42(1):524. 